\title{
Sexual assault reported at a law enforcement health facility in Makurdi, North-central Nigeria
}

\author{
Utoo $\mathrm{BT}^{1 *}$, Ilora $\mathrm{E}^{2}$ and Utoo $\mathrm{PM}^{3}$ \\ ${ }^{1}$ Department of Obstetrics and Gynecology, Benue State University Teaching Hospital, Makurdi, Nigeria \\ ${ }^{2}$ Department of Family Medicine, Irrua Specialist Teaching Hospital, Irrua, Edo State, Nigeria \\ ${ }^{3}$ Department of Epidemiology and Community Health, Benue State University Teaching Hospital, Nigeria
}

\begin{abstract}
Background: Sexual assault is a social problem of public health concern worldwide. It is a violation of the rights of victims irrespective of gender.

Objective: This study was design to assess the incidence, profile of victims and clinical presentation by victims of reported cases of rape at the health facility.

Methods: The study was a prospective assessment of rape cases seen at the Police clinic Makurdi, Nigeria over a period of 21 months. The data was collected with a proforma and analyzed using SPSS version 20. Chi Square was used as a test of statistics with P-value of 0.05 (95\% CI) as statistical significance.

Results: Within the study period, 178 gynecological cases were managed out of which 46 were rape cases given an incidence of $25.8 \%$. Average age of victims was $14 \pm 0.9$ years. The most affected age group is pre-teens ( $8-12$ years) $39.1 \%$ and teens (13-18years) $34.8 \%$, majority therefore been pupils/students $84.4 \%$ of primary schools (50.0\%) and secondary (34.8\%) education. Majority of them staying in urban environment (82.6\%) with both parents (50\%). The commonest clinical presentation was abnormal vaginal discharge (23.9\%), bleeding $(21.7 \%)$ and genital tear $(21.7 \%)$. In most cases the victim was assaulted by one assailant (91.3\%), at his home (56.5\%), in the afternoon (43.5\%) and he was either a friend/acquaintance (39.1\%) or stranger (34.8\%). Only $39.1 \%$ of victims presented within 24 hours of the incident.
\end{abstract}

Conclusion: Sexuality education by parents and school authorities as well as legislation against this crime and punishment of offenders will halt the rampant trend of this malady.

\section{Introduction}

Sexual assault is a worldwide crime mostly committed against women. It is a form of sexual violence in which the sexual activity is unwanted, non-consensual and with application of physical force, threat or verbal intimidation of the victim [1-3]. In assault the force used is immediate, short duration or infrequent [1]. It is a brutal form of violation of the rights of women that has been condemned worldwide $[4,5]$. It has been under-reported majorly because of the intent of protecting victims; avoidance of stigmatization, lack of successful prosecution of offenders and the fact that our society is predominantly male dominated $[2,5,6]$.

It is however unfortunate that its prevalence is on the increasing trend especially in societies with high rates of poverty, social and moral decadence, drug abuse, breakdown of family values and general violent unrest [6]. The prevalence of sexual assaults has been reported variously in different societies; $8.6 \%$ in USA, Democratic Republic of Congo 16\%, Ethiopia 14.3\%, and South Africa 24.9\% [2]. In Nigeria rates of $0.06 \%$ in Zaria, $0.76 \%$ in Lagos, $2.1 \%$ in Calabar, $5.2 \%$ in Ife, $5.6 \%$ in Jos, $2.1 \%$ in Oshogbo and $0.2 \%$ in Mina have been reported $[1,3]$.

Rates in community-based studies are obviously higher than the urban facility-based studies. A woman who is sexually assaulted faces a lot of social, medical and psychological problems in the immediate and long term. Problems such as genital tract traumas leading to bleeding, fistulas; abnormal vaginal discharges, sexually transmitted infections including HIV/AIDS, unwanted pregnancies leading to unsafe abortions and their sequellae as well as sexual disorders and mental illnesses just to mention a few $[2,3,5]$. Perpetrators of this crime are usually said to be family members, friends, acquaintances much more than strangers $[4,6,7]$.

The assailant could be alone or more in number as in gang rape [8]. Some victims have been sexually assaulted more than once leaving a long-term scar on the life and reproductive career of those victims [6]. The laws in Nigeria against this crime have not been implemented fully against offenders thereby paving way for the perpetuation of the crime [3,7]. It is reported that only about $28 \%$ of sexual assaults have been reported to the law enforcement agents for arrest and subsequent prosecution of offenders. No study of this nature has been reported in the literatures from Benue state of Nigeria hence the need to conduct this research; the aim therefore is to determine the incidence, profile of victims and clinical presentation of sexually assaulted victims as seen at the police clinic in Makurdi.

${ }^{*}$ Correspondence to: Bernard Terkimbi Utoo, Senior Lecturer/Consultant Obstetrician and Gynecologist, Benue State University Teaching Hospital, Makurdi, Nigeria, Tel: +2348033725168, +2348179614268; E-mail: bernardutoo@yahoo.com; utoobt86@gmail.com

Received: December 07, 2018; Accepted: December 20, 2018; Published: December 24, 2018 


\section{Materials and methods}

Study Area: The study was conducted in Makurdi, the capital of Benue State in North Central Nigeria. The state is called the food basket of Nigeria due to its great agricultural potentials. The inhabitants are predominantly farmers, civil servants and petty traders. The major ethnic groups are; Tiv, Idoma and Igede.

Study Population: This comprise of all victims who reported to the Clinic for sexual assault within the study period irrespective of age.

Study Design: This was a longitudinal prospective study. Victims who were brought to the clinic by a police officer in company of relations for investigation and treatment were interviewed and the information recorded into a proforma designed for the study. The information documented included; social demographic characteristics of the victim, where and when the incidence occurred, profile of assailant, number of assailants involved, weapon used if any, relationship between assailant and victim, injuries sustained by victim, number of times victim has been assaulted, clinical presentation and time of presentation to the clinic.

Study setting: This is a facility-based study conducted at the police Clinic in Makurdi. The clinic is located in the police headquarter in Makurdi metropolis. The clinic is a cottage health facility with 4 medical officers. The gyneacology department has 5 nurses and a senior registrar in Obstetrics and Gynaecology from the Federal Medical Centre Makurdi who visit regularly. There are 11 bed spaces for inpatient treatment, laboratory for basic tests and a pharmacy.

Sample Size: The sample size was estimated using the Fisher's formula below

$$
n^{1}=\frac{z^{2} p}{d^{2}}
$$

$\mathrm{n}=$ The desired sample size

$\mathrm{Z}=$ The standard normal deviate usually set at 1.96 which corresponds to the $95 \%$ confidence interval.

$\mathrm{P}=$ The proportion in the target population estimated to have been sexually assaulted as reported in Calabar [1].

$$
\mathrm{P}=2.1 \%(0.021)
$$$$
\mathrm{q}=1.0-\mathrm{p}(1.0-0.021=0.979) \text {. }
$$

$\mathrm{d}=$ the degree of accuracy desired, usually set at 0.05 level.

$\mathrm{N}=(1.96)^{2} \mathrm{X} 0.021 \mathrm{X} 0.979 /(0.05)^{2}=31.6$. The sample size was however increased to 46 to give room for $10 \%$ attrition rate and to increase the statistical power (Tables 1 and 2).

\section{Ethical consideration}

This study was approved by the ethics and research committee of the Benue State University Teaching Hospital (BSUTH) Makurdi.

\section{Results}

Within the study period, 178 gynecological cases were managed out of which 46 were rape cases given an incidence of $25.8 \%$. The mean age was $14 \pm 0.9$ years. The most affected age group was pre-teens (8-12years) $39.1 \%$ and teens (13-18years) $34.8 \%$, infantile patients constituted $15.2 \%$, majority therefore been pupils/students $84.4 \%$ of primary schools (50.0\%) and secondary (34.8\%) education. Majority of

\begin{tabular}{|c|c|c|}
\hline Variable & Frequency & Percent (\%) \\
\hline \multicolumn{3}{|l|}{ Age } \\
\hline 0-7 Years & 7 & 15.2 \\
\hline $8-12$ Years & 18 & 39.1 \\
\hline 13-18 Years & 16 & 34.8 \\
\hline 19-50 Years & 5 & 10.9 \\
\hline \multicolumn{3}{|l|}{ Occupation } \\
\hline Student & 39 & 84.8 \\
\hline Hawker/Trader & 5 & 10.9 \\
\hline Applicant & 1 & 2.2 \\
\hline Civil Servant & 1 & 2.2 \\
\hline \multicolumn{3}{|l|}{ Educational Status } \\
\hline Primary & 23 & 50.0 \\
\hline Secondary & 16 & 34.8 \\
\hline Tertiary & 4 & 8.7 \\
\hline Pre-School & 2 & 4.3 \\
\hline None & 1 & 2.2 \\
\hline \multicolumn{3}{|l|}{ Residence } \\
\hline Urban & 38 & 82.6 \\
\hline Rural & 8 & 17.4 \\
\hline \multicolumn{3}{|l|}{ Resides with/in } \\
\hline Both parents & 23 & 50.0 \\
\hline Other relative & 11 & 23.9 \\
\hline Stepfather & 5 & 10.9 \\
\hline Single Mother & 5 & 10.9 \\
\hline Strangers & 1 & 2.2 \\
\hline Institutional Homes & 1 & 2.2 \\
\hline \multicolumn{3}{|l|}{ Marital Status } \\
\hline Child & 26 & 56.5 \\
\hline Single & 18 & 39.1 \\
\hline Married & 2 & 4.3 \\
\hline \multicolumn{3}{|l|}{ Menstrual History } \\
\hline Post Menarche & 26 & 56.5 \\
\hline Pre Menarche & 20 & 43.5 \\
\hline \multicolumn{3}{|l|}{ Sexual History } \\
\hline Active & 26 & 56.5 \\
\hline Inactive & 20 & 43.5 \\
\hline
\end{tabular}

Table 1. Personal data of victim

the victims stay in urban environment $(82.6 \%)$ while $17.4 \%$ were rural dwellers. Most were staying with both parents (50\%). Only $4.3 \%$ of victims were married, $39.1 \%$ were single girls and $56.5 \%$ were children. The commonest clinical presentation was abnormal vaginal discharge (23.9\%), bleeding $(21.7 \%)$ and genital tear $(21.7 \%)$. In most cases the victim was assaulted by one assailant $(91.3 \%)$ and at the home of the assailant (56.5\%). Most of this crime was committed in the afternoon (43.5\%), 28.3\% in the evening, $19.6 \%$ night and only $8.7 \%$ in the morning. In most cases the assailant was either a friend/acquaintance $(39.1 \%)$ or stranger $(34.8 \%)$. One-third of the victims were experiencing rape for the first time. Only $39.1 \%$ of victims reported the incident within 24 hours.

\section{Discussion}

The study finds an incidence of $25.8 \%$. This is overwhelmingly higher than any of the published rates in Nigeria. It is however similar to that of $24.9 \%$ reported in South Africa. We are however not surprised at the high incidence recorded at the facility because rape is a medico-legal issue. The study setting is police clinic where cases of sexual assaults reported to the law enforcement agents are attended to medically. South Africa that has similar reported rates has been recognized for generations as the "headquarter" of rape in the world. 
Table 2. Presentation of victims to the clinic

\begin{tabular}{|c|c|c|}
\hline Variable & Frequency & Percent $(\%)$ \\
\hline \multicolumn{3}{|l|}{ Presenting Complaint } \\
\hline Abnormal Vaginal Discharge & 11 & 23.9 \\
\hline Bleeding Per Vaginal & 10 & 21.7 \\
\hline Genital Tears & 10 & 21.7 \\
\hline Amenorrhea & 8 & 17.4 \\
\hline Others & 7 & 15.2 \\
\hline \multicolumn{3}{|l|}{ Time of Incidence } \\
\hline Afternoon & 20 & 43.5 \\
\hline Evening & 13 & 28.3 \\
\hline Night & 9 & 19.6 \\
\hline Morning & 4 & 8.7 \\
\hline \multicolumn{3}{|l|}{ Place of Incidence } \\
\hline Assailant's Home & 26 & 56.5 \\
\hline Home Shared by both Victim \& Assailants & 6 & 13.0 \\
\hline Victim's House & 5 & 10.9 \\
\hline Assailant's place of work & 4 & 8.7 \\
\hline Victim's place of work/school & 3 & 6.5 \\
\hline Bush/Vehicle & 2 & 4.3 \\
\hline \multicolumn{3}{|l|}{ Time Spent before Presentation } \\
\hline Less than 24 hours & 18 & 39.1 \\
\hline $24-72$ hours & 18 & 39.1 \\
\hline Greater than 1 week & 7 & 15.2 \\
\hline 72 hours - 1 week & 3 & 6.5 \\
\hline \multicolumn{3}{|l|}{ Previous History of Rape } \\
\hline None & 31 & 67.4 \\
\hline $1 \mathrm{x}$ & 12 & 26.1 \\
\hline$>2 x$ & 2 & 4.3 \\
\hline $2 \mathrm{x}$ & 1 & 2.2 \\
\hline \multicolumn{3}{|l|}{ HIV Status } \\
\hline Unknown & 28 & 60.9 \\
\hline Sero Negative & 18 & 39.1 \\
\hline
\end{tabular}

This is to illustrate how frequent this violent crime against women is committed in that country.

Although the crime of sexual assault against women has assumed a worldwide dimension the involvement of preteens and teenagers is extremely worrisome. This finding is similar to the reports of a good number of studies done in Nigeria $[1,3,8,9]$. Actually, rape among this group of the population is more likely to be reported to the law enforcement agent [1]. It is worthy to mention that this age bracket has not yet begun their reproductive carrier and the negative consequence of this abuse is bound to have not only an immediate but long-term impact on their lives.

The myth propagated in some parts of the world about the cure of STIs such as HIV by a male who have sex with a virgin girl few years ago did a lot of harm towards violation of the sexual rights of women [6]. The communal lifestyle in African nations which has dismantled sociocultural barriers among people in the communities is also contributory, coupled with the breakdown of cultural values thereby promoting immoral activities among the youths. Advancement in technology and increasing westernization of our societies has also played a negative role. Crimes against humanity of this nature could also have been prompted by anger as a result of frustration from joblessness, poverty, illiteracy and the general lawlessness in the society [6]. In some cases, the men wants to demonstrate their dominance over the female victim rather than sexual pleasure.

The abuse of these young girls of primary and secondary school age is a wakeup call to both parents and school authorities. Parents are admonished never to shy away from sexuality education any more. Gone are the days that parents hid sexuality education from their children with the fear that they will become wayward. Children must be empowered with the relevant information so as to build their capacity to overcome the traps set by people who want to take advantage of their ignorance to violate their sexual rights $[10,11]$. By the way if we do not educate our children in this regard, they will still learn but from wrong sources. Some studies have reported sexual harassment in schools by boys, teachers and other male workers towards young girls through verbal and physical contacts [10]. The school curriculum of these children who are at the formative years should take into consideration this aspect of societal complexity [11]. Girls of school age should also be taught on how to dress well and not provocatively in such a manner that attracts violators. A dress code in all the schools can help in this regard.

Another worrisome finding which has also been reported in other studies is the involvement of family members, acquaintances and friends as assailants [12]. Sometimes, close relations such as father, brother, cousin, nephew, friends to parents or victims themselves are implicated. The victims in most cases are unsuspecting because of the level of trust and confidence they have in the culprits. Sometimes prosecuting offenders could also be hampered by this close family ties. There has to be measures put in place at home, school, and other public places to protect the girl child from sexual assault [11]. The finding that most of these crimes were committed in the day time is in keeping with the usually reported social demographic profile of victims in this age group. They are usually very young, pupil/college, single girls. Rape of Juvenile victims has been found to occur in the day time during school hours unlike that of adults that occur after midnight [1,5].

Genital tract injuries, vaginal bleeding and vaginal discharge were common clinical presentation findings amongst the victims [8]. This is an incident with not only physical but psychological trauma for the victims. Unfortunately, a good number report to the clinic late as was the case in this study in which only $39.1 \%$ reported within 24 hours of the incident. Most victims report late because of fear as a result of treats to their lives by assailants or their acquaintances. Victims also want to avoid stigmatization which may affect their self-esteem as well as the possibility of getting a good suitor. Some of these cases are not even reported because of the involvement of family relations [13-15].

The absence of legislation in some climes against rape as well as lack of successful prosecution and punishment for offenders makes under reporting common $[13,14]$. The different definition of rape amongst various cultures, and even the law needs to be looked into, for example some societies will not see forceful sexual exploitation of a young woman by her boyfriend as rape. Some children also do not acknowledge that sex with an elderly man was actually sexual abuse. Law enforcement agents may even make mockery of sexual violence involving intimate partners [15].

The finding of more cases of this violent crime amongst urban dwellers has brought to fore the need for a more intensive policing of our societies to curb these vices. If community policing as been suggested in some quarters and subscribed to by the top brass of the Nigerian police force could be implemented as well as equipping and catering for the warfare of the force to motivate them in fighting criminality, such crimes could be reduced to the barest minimum [16].

The absence of rape kit and other essential instruments for proper investigation and treatment of rape victims makes the care of victims suboptimal [14]. If clinics in towns and cities lack the necessary equipping for medical care of rape victims, then one can imagine the 
suffering faced by rape survivors in the community where more of these crimes take place. There is no uniform protocol in managing victims and follow up programs to handle post-traumatic stress disorders and even suicidal ideation that may arise after rape [17]. Taiwo MO et al enumerated several other psychological consequences of sexual harassment to include among the following; persistent sadness, negative outlook, irritability, mood swings, impulsivity, emotional flooding, anxiety, fears of loss of control, excessive guilt and shame, escape fantasies, compulsive thoughts, rage episodes, obsession fears, crying spells, persistent anger and fear, decreased self-esteem, self-doubt, diminished self-confidence, decreased concentration, feelings of humiliation, helplessness, vulnerability and alienation. Psychiatric disorders reported have included anxiety disorders, acute stress disorder, dissociation disorders, somatization disorders, sleep disorders, sexual dysfunction disorders, psychoactive substance abuse disorders, depressive disorders and adjustment disorders [18-21].

More workshops and trainings for health workers on rape are needed to increase awareness and build capacity of personnel in handling rape cases that present to the hospital. There should also be capacity to do forensic assessment of assailants so as to stop the network of rape offenders, which is catching up with and administering punitive measures on individuals who commit the crime in a locality and escape to another to commit similar crime.

Unfortunately the survivors did not only present late for treatment but were also lost to follow up which is again an indication that they may not want much publicity because of stigmatization and the fact that a good number of the assailants were acquaintances or people known to the victims. This is similar to the findings in similar other studies [19]. This however makes evaluation of victims to ascertain long term complications and further treatment difficult. More enlightenment campaigns are needed to encourage victims present early for treatment [22]. Also, campaigns against rape should seek to encourage victims to speak out irrespective of how the offender is related to the victim (Figures 1 and 2).

Civil societies, religious bodies, non-governmental organizations as well as civil right activists should roll out their drums against rape in order to augment the efforts of government in fighting rape.

\section{Conclusion}

The incidence of rape in the study is $25.8 \%$. Most of the victims are pre-pubertal and teenage girls that presented with genital tract injuries, vaginal bleeding and discharge. Sexuality education, legislation and punishment of offenders will reduce the increasing trend of rape.

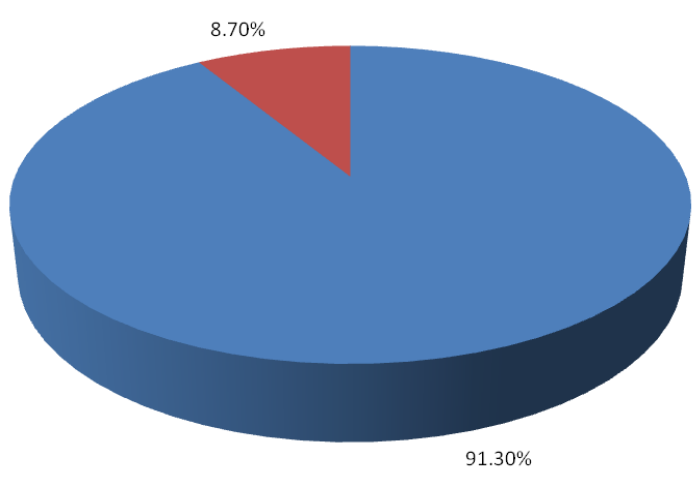

Figure 1. Number of assailants

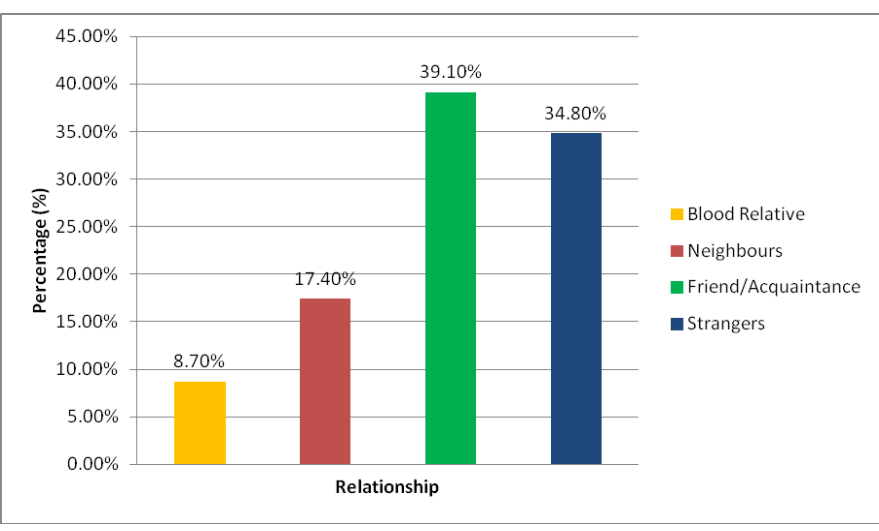

Figure 2. Relationship with assailant

\section{Acknowledgement}

We appreciate the cooperation of Nurses and Medical officers at the police clinic in Makurdi during data collection. We thank Victor Adagba for helping with data entry.

\section{Conflict of interest}

Authors declare they have no conflict of interest

\section{Author's contribution}

All authors contributed to conceptualization, design and approval of final manuscript. BTU wrote the initial manuscript, EI collected the data; PMU did data analysis and interpretation. All authors have approved the publication of the manuscript.

\section{References}

1. Mairo H, Kehinde JA, Abubakar SN, Karima T, Amina GU, et al. (2016). Prevalence and pattern of sexual assault in Usmanu Danfodiyo University Teaching Hospital, Sokoto, Nigeria. Pan Afr Med J 24:332. [Crossref]

2. Mezie-Okoye MM, Alamina FF (2014) Sexual violence among female undergraduates in a tertiary institution in Port Harcourt: prevalence, pattern, determinants and health consequences. Afr J Reprod Health 18: 79-85. [Crossref]

3. Daru PH, Osagie EO, Pam IC, Mutihir JT, Silas OA, et al. (2011) Analysis of cases of rape as seen at the Jos University Teaching Hospital, Jos, North Central Nigeria. Niger J Clin Pract 14: 47-51. [Crossref]

4. Badejoko OO, Anyabolu HC, Badejoko BO, Ijarotimi AO, Kuti O, et al. (2014) Sexual assault in Ile-Ife, Nigeria. Niger Med J 55: 254-259. [Crossref]

5. Umeora OUJ, Obuna JA (2015). A Survey into the Prevalence and Pattern of Rape in a Nigerian Tertiary Institution. Inter J Innov Sci Res 13: 349-353.

6. Odu B, Falana B K, Olotu OA (2014) Prevalence of Violent Sexual Assault on South West Nigeria Girls. Eur Sci J 10: 471-481.

7. Esere MO, Idowu AI, Durosaro IA, Omotosho JA (2009). Causes and Consequences of Intimate Partner Rape and Violence: Experiences of Victims in Lagos, Nigeria. $J$ Aids HIV Res 1: 001-007.

8. Olusanya O, Ogbemi S, Unuigbe J, Oronsaye A (1986) The pattern of rape in Benin City, Nigeria. Trop Geogr Med 38: 215-220. [Crossref]

9. Lakew Z (2001) Alleged cases of sexual assault reported to two Addis Ababa hospitals. East Afr Med J 78: 80-83. [Crossref]

10. Ekabua JE, Agan TU, Iklaki CU, Ekanem EI, Itam IH, et al. (2006) Risk factors associated with sexual assault in Calabar south eastern Nigeria. Niger J Med 15: 406408. [Crossref]

11. Danielson CK, Holmes MM (2004) Adolescent sexual assault: an update of the literature. Curr Opin Obstet Gynecol 16: 383-388. [Crossref]

12. Haugen K, Slungård A, Schei B (2005) [Sexual assault against women-- injury pattern and victim-perpetrator relationship]. Tidsskr Nor Laegeforen 125: 3424-3427. [Crossref] 
13. Duru CO, Ederiane OE, Akinbami FO (2014) Child Sexual Abuse: A Review of Cases Presenting at the out-patient Clinic of a Tertiary Health Centre inBayelsa State, Nigeria. Global Adv Res J Med Medical Sci 3: 354-361.

14. Oluwa AW, Peters AO (2010) Causes and Incidence of Rape among Middle Aged and Young Adults in Lagos State, Nigeria. Res J Biol Sci 5: 670-677.

15. Richard AA (2014) "It Couldn't Have Been Rape": How Social Perception and RapeScripts Influence Unacknowledged Sexual Assault in Nigeria. Research on Humanit Soc Sci 4(8):

16. Ahmed YA (2012) The Pattern and Distribution of Crime Incidence in an UrbanEnvironment: A Case study of Osun State, South Western Nigeria. Int J Humanit Soc Sci 2:178-188.

17. Isa A, Lawal WU, Hafsatu HM, Shuaibu M, Olusegun AO, et al. (2011). Child Sexua Abuse: A Review of Cases Seen at General Hospital Suleija, Niger State. Annals of Nigerian Medicine 5:15-19.
18. Taiwo MO, Omole OC, Omole OE (2014) Sexual Harassment and Psychological Consequence among Students in Higher Education Institution in OsunState, Nigeria. Int J Appl Psychol 4: 13-18.

19. Ashimi A, Amole T, Ugwa E (2015) Reported Sexual Violence among Women and Children Seen at the Gynecological Emergency Unit of a Rural Tertiary Health Facility, Northwest Nigeria. Ann Med Health Sci Res 5: 26-29. [Crossref]

20. Ogunfowokan AA, Fajemilehin BR (2015). Experiences of Sexual Abuse by Adolescent Girls in Ife/Ijesa Zone, Nigeria. Niger J Health Sci 15:89-97.

21. Aborisade RA, Vaughan Fidelia FE (2014) The Victimology of Rape in Nigeria: Examining Victims' Post-Assault Experiences and Adjustment Patterns. Afri J Psych Stud Soc Issues 17: 140-155.

22. Sendo EG, Meleku M (2015) Prevalence and Factors Associated with Sexual Violence among Female Students of Hawassa University in Ethiopia. Science post print 1: e00047. 10.14340/spp.04a0002.

Copyright: (C2018 Utoo BT. This is an open-access article distributed under the terms of the Creative Commons Attribution License, which permits unrestricted use, distribution, and reproduction in any medium, provided the original author and source are credited. 